\title{
UMA ANALISE CRÍTICA DA CRIAÇÃO DE UM TRIBUNAL CONSTITUCIONAL INTERNACIONAL COMO APLICADOR DE UM SISTEMA JURÍDICO MULTINÍVEL
}

\author{
A CRITICAL ANALYSIS OF THE ESTABLISHMENT OF AN INTERNATIONAL \\ CONSTITUTIONAL COURT AS APPLICATOR OF A MULTI-LEVEL LEGAL \\ SYSTEM
}

UN ANÁLISIS CRÍTICO DE LA CREACIÓN DE UN TRIBUNAL CONSTITUCIONAL INTERNACIONAL COMO APLICADOR DE UN SISTEMA JURÍDICO MULTINIVEL

Licença CC BY:

Artigo distribuído sob os termos Creative Commons, permite uso e distribuição irrestrita em qualquer meio desde que o autor credite a fonte original.

\section{Régis Willyan da Silva Andrade ${ }^{1}$ Luiz Nunes Pegoraro²}

1 Pós-doutorando em Direito Constitucional pela FDSM/MG (2017), Bolsista CAPES, Doutor em Direito Constitucional pela Pontifícia Universidade Católica de São Paulo PUC/SP (2016), sob a orientação da Prof. Dra. Flávia Piovesan. Mestre em Direito pela Faculdade de Direito do Sul de Minas FDSM/MG (2012), sob a orientação do Prof. Dr. Eduardo Henrique Lopes Figueiredo. Especialista em Direito Constitucional pela Faculdade de Direito do Sul de Minas FDSM (2009). Curso de Extensão realizado na Faculdade de Direito da Universidade de Coimbra/Portugal (2009), por força do intercâmbio do Programa de Mestrado da Faculdade de Direito do Sul de Minas. Especialista em Direito e Processo do Trabalho pela Universidade para o Desenvolvimento do Estado do Paraná e Região do Pantanal UNIDERP (2010). Especialista em Direito Processual Civil pela Faculdade de Direito do Sul de Minas FDSM (2011). Graduado em Direito pela Faculdade de Direito do Sul de Minas FDSM (2007). Atualmente é docente pesquisador vinculado a grupos avançados de estudos em Direitos Humanos e Constitucional da Pontifícia Universidade Católica de São Paulo PUC/SP, sob a orientação da Professora Dra. Flavia Piovesan. Consultor jurídico, conferencista e parecerista. Possui livro publicado com outros autores na área do Direito Constitucional, além de vários ensaios publicados em revistas jurídicas especializadas e material didático em Direito Constitucional. Editor do Grupo de Pesquisas SAPERE-AUDE (2015-2017), membro do Grupo de Pesquisas LIDE 2.0, coordenado pelo Prof. Dr. Elias Kallas Filho, membro do grupo de pesquisas. Novas Configurações Institucionais da Democracia Brasileira, coordenada pelo prof. Dr. Rafael Lazzarotto Simioni. Possui experiência na área do Direito, com ênfase para Direitos Constitucional e Direitos Humanos, Direito e Processo do Trabalho, Direito Processual Civil e Direito Ambiental. Possui experiência em gestão e avaliação acadêmica de Cursos de Direito, através da atuação como membro integrante e consultor em Conselhos de Ensino e Pesquisa universitários, de Conselhos Departamentais, de Núcleo de Docentes Estruturantes (NDE) e de Colegiados de Curso, além do exercício de supervisão de Núcleos de Prática Jurídica (NPJ) e de Núcleos de Trabalhos de Conclusão de Curso (TCC). Advogado inscrito na Ordem dos Advogados do Brasil da $23^{\text {a }}$ Subsecção de Minas Gerais. E-mail: regis@jansennogueira.adv.br.

2 Advogado; Doutor em Ciências da Reabilitação pela USP (2016); Mestre em Direito Constitucional pela Instituição Toledo de Ensino (2007) e Especialista em Direito Público pela ITE (2008). Graduado em Direito pela Instituição Toledo de Ensino de Bauru (1997). 
Resumo: O presente artigo se assenta na necessidade de um sistema multinível de proteção para que os direitos fundamentais sejam efetivos, bem como a análise de um diálogo entre as cortes constitucionais quanto à inderrogabilidade desses direitos. Adota-se a metodologia analítica documental para tanto. Tem-se que a problemática da questão reside na base dos direitos fundamentais, qual seja, a dignidade da pessoa humana, fundamento que orienta uma pluralidade de elementos essenciais e suporte maior para a concepção de tais direitos e, ainda, princípio no qual se pautam os principais sistemas constitucionais modernos. O Estado deveria fomentar e respeitar a existência digna do ser humano, valorizando-o tanto em sua dimensão individual quanto num contexto de justiça para que o estímulo do diálogo entre as Cortes Constitucionais propicie a criação de um sistema jurídico multinível de proteção desses direitos.

Palavras-chave: Diálogo Constitucional; Direitos Fundamentais; Direitos Humanos; Inderrogabilidade; Sistema Multinível.

\begin{abstract}
This article is based on the need for a multi-level system of protection for fundamental rights to be effective, as well as the analysis of a dialogue among the constitutional courts regarding the non-eligibility of these rights. The documentary analytical methodology is adopted for this purpose. The problem question relates to that fundamental rights, i.e. the dignity of the human person, a foundation that guides a plurality of essential elements and a greater support for the conception of these rights, and also a principle in which the main modern constitutional system are based. The State should foster and respect the dignified existence of the human being, valuing it both in its individual dimension and in the context of justice, so that the stimulus of dialogue between the Constitutional Courts promotes the creation of a multilevel legal system for the protection of these rights.
\end{abstract}

Keywords: Constitutional Dialogue. Fundamental Rights. Human Rights. Non-derogability. Multi-level system.

Resumen: El presente artículo se basa en la necesidad de un sistema multinivel de protección para que los derechos fundamentales sean efectivos, bien como el análisis de un diálogo entre las cortes constitucionales como a la inderogabilidad de estos derechos. Se adopta la metodología analítica documental para tanto. Se trata de que la problemática de la cuestión reside en la base de los derechos fundamentales, cualquier sea, la dignidad de la persona humana, fundamento que orienta una pluralidad de elementos esenciales y soporte mayor para la concepción de tales derechos, e incluso, principio en el cual se pauta los principales sistemas constitucionales modernos. El Estado debería fomentar y respetar la existencia digna del ser humano, valorizándolo tanto en su dimensión individual como en un contexto de justicia para que el estímulo de diálogo entre las Cortes Constitucionales propicie la creación de un sistema jurídico multinivel de protección de estos derechos.

Coordenador do Curso de Direito do Centro Universitário de Bauru/SP, mantido pela Instituição Toledo de Ensino (ITE). Membro do Núcleo Docente Estruturante do Curso de Direito do Centro Universitário de Bauru. Membro do Colegiado de Curso de Graduação em Direito do Centro Universitário de Bauru. Membro titular do Comitê de Ética em Pesquisa em Seres Humanos do HRAC-USP na área Jurídica. Professor do Centro Universitário de Bauru Instituição Toledo de Ensino e na Faculdade Iteana de Botucatu nas matérias Direito Administrativo, atualização legislativa e Ciência Política e Direito Constitucional. Professor dos Cursos de Mestrado e Doutorado do Centro Universitário de Bauru/SP. Tem experiência na área de Direito, com ênfase em Direito Administrativo, atuando principalmente em improbidades administrativas, licitações, contratos administrativos, desapropriações, políticas públicas e agentes públicos. Foi Secretários dos Negócios Jurídicos dos Municípios de Piratininga nos anos de 2006 a 2008 e do Município de Bauru nos anos de 2009 e 2010. E-mail: professor@pegoraros.com.br. 
Palabras-clave: Diálogo Constitucional; Derechos Fundamentales; Derechos Humanos; Inderogabilidad; Sistema Multinivel.

\section{INTRODUÇÃO}

A internacionalização dos Direitos Humanos pós Segunda Guerra Mundial surge como o novo paradigma ético, no intuito de restaurar a lógica do razoável, rompendo com o totalitarismo desenvolvido ao longo do século $X X$, que negava que a pessoa humana pudesse ser a fonte do direito, o que fez emergir a necessidade de reconstruir os Direitos Humanos, aproximando o direito da moral.

O desafio nesse contexto é reestabelecer a ordem internacional com parâmetros que busquem um núcleo inderrogável de direitos, em observância à dignidade da pessoa humana, e que possa apresentar instrumentos capazes de garantir a eficácia destes direitos, por meio da introdução da ética e da moral ao se estabelecer normas tanto globais quanto domésticas que estimulem o diálogo interestatal, a fim de se criar uma Constituição Internacional e um Tribunal Constitucional capaz de aplicar sanções tanto aos indivíduos quanto aos Estados.

A metodologia utilizada é a analítica documental, partindo-se de referenciais teóricos que abordam o tema como Maurício Ramires, Claire L'heureux-Dubé, A. M. Slaughter, Liliana Galdámez Zelada, entre outros.

No entanto, para a criação de uma Carta Constitucional Internacional, este conceito de intervenção tem sido um tema relevante no debate do Direito Internacional, haja vista uma confusão sobre a esfera de atuação. Autores como L'heureux-Dubé e Ramires sustentam consistir apenas em assuntos internos, como na mudança forçada da forma de governo; outros questionam se também abrange os problemas de natureza externa, como a imposição de normas de proteção aos direitos fundamentais em relação à política exterior.

Percebe-se que, para se estabelecer um núcleo inderrogável de direitos na esfera global, são necessários sacrifícios, na ordem da delimitação da soberania estatal, submetendo-se a órgãos ou comissões internacionais que podem aplicar sanções em caso de descumprimento ou violação a direitos e garantias voltados à proteção da pessoa humana. 
A atuação e a aplicabilidade desses ideais apresentam enormes dificuldades no que tange ao reconhecimento dessa situação jurídica, como a eficácia das normas de direito internacional humanitário, a atuação somente nas situações de emergência humanitária advinda de conflitos armados e a aspiração de garantir juridicamente o livre acesso das vítimas de catástrofes humanitárias.

Acerca dos desafios de se estabelecer um núcleo inderrogável de direitos em âmbito global, há que se considerar as diferenças sociais, culturais e econômicas de cada região, percebendo-se que a proteção dos direitos humanos por meio de instituições de âmbito regional se revela mais positiva, na medida em que os Estados situados num mesmo contexto geográfico, histórico e cultural têm maior probabilidade de transpor os obstáculos apresentados em âmbito mundial.

A partir destas premissas é possível analisar a evolução do constitucionalismo na América Latina, destacando como cada Estado trata a questão da inderrogabilidade de seus direitos, criando assim um núcleo duro, capaz de orientar não apenas a legislação infraconstitucional, mas de servir de quadro para emoldurar um Direito Constitucional, capaz ao mesmo tempo de respeitar a diversidade e de servir como uma base supranacional.

O desenvolvimento dessa nova modalidade de constitucionalismo coaduna com as perspectivas de um movimento dinâmico, capaz de atender às necessidades de uma sociedade cada vez mais complexa, e que exige dos operadores do direito o discernimento para ultrapassar velhos conceitos ligados à soberania, capaz de auxiliar na solução de conflitos com diferentes estratégias por dois ou mais sistemas jurídicos constitucionais.

Desta forma, surgem algumas teorias, dentre elas a de um Diálogo Judicial Internacional, como proposta por Mauricio Ramires, que visam fundamentar essas relações interestatais, aproveitando a legislação estrangeira, dentro de suas Cartas Constitucionais e promovendo o intercâmbio de elementos constitucionais entre agentes supostamente autossuficientes.

Deve-se observar que o uso da jurisprudência estrangeira pelos tribunais constitucionais parte da premissa de precedentes, assim como o modelo norteamericano parte de decisões pretéritas que servirão de modelo para decisões 
mais recentes (por meio das lições do passado é possível aplicar conceitos visando à resolução de casos concretos no futuro).

Assim, a presente pesquisa tem como problemática a ineficácia dos meios utilizados para se dar efetividade às normas fundamentais, seja em âmbito doméstico ou internacional, bem como a hipótese pauta-se na necessidade de se fomentar o diálogo entre as Cortes Constitucionais, a fim de que novos sistemas, como o multinível, possam ser disseminados para proteção e efetividade desses direitos.

O que se busca por meio desta pesquisa como objetivo geral é demonstrar a necessidade de se estabelecer um diálogo verdadeiro entre os tribunais, a fim de que os precedentes possam ser utilizados como forma de efetivação dos direitos fundamentais.

Eis que os objetivos específicos partem dos desafios dos Direitos Humanos Fundamentais numa perspectiva multinível: criar a ponte capaz de realizar o diálogo entre as cortes constitucionais como uma via de mão dupla, e não apenas impor o sistema de países desenvolvidos em face aos países em desenvolvimento, que serviram de fundamento para efetivar esses direitos em âmbito infra e supranacional, buscando dar efetividade aos direitos consagrados nas Cartas Constitucionais.

\section{O DIÁLOGO NECESSÁRIO ENTRE A JURISPRUDÊNCIA DO SUPREMO TRIBUNAL FEDERAL E OS SISTEMAS DE PROTEÇÃO DOS DIREITOS HUMANOS FUNDAMENTAIS}

O pensamento jurídico como atividade judicial ingressou numa nova era ou etapa, marcada pelas crescentes influências recíprocas das jurisprudências nacionais e internacionais umas sobre as outras. Nesse sentido, em 1994, a acadêmica norte-americana Anne-Marie Slaughter ${ }^{3}$ publicou um trabalho que iniciava com uma frase destinada a se tornar célebre: "Os tribunais estão conversando entre si em todo o mundo".

3 SLAUGHTER, A.M. A typology of transjudicial communication. University of Richmond Law Review. v.29, n.99. Richmond, 1994, p. 99.

4 "The courts are talking to each other around the world". 
A internacionalização da influência da jurisprudência constitucional remete à extensão que ultrapassa as fronteiras da força gravitacional dos entendimentos exarados em sentenças ou precedentes que tratam de hermenêutica constitucional. Desta forma, uma interpretação dada em âmbito doméstico de um aspecto da Constituição exerce influência em outras Cortes Constitucionais em um problema de interpretação de outra Lei Fundamental.

O ponto a ser destacado é se essas relações são recíprocas ou não, fomentando um verdadeiro diálogo, ou se ainda se trata de tribunais de países mais desenvolvidos que influenciam na tomada de decisões de países em desenvolvimento. Entre os adeptos da corrente do diálogo constitucional:

Essas relações são recíprocas: apesar de ainda se poder identificar alguns tribunais como mais influentes do que outros no que se refere à propagação externa de sua jurisprudência, as referências aos julgados estrangeiros têm se tornado mútuas, mediante constantes e difusos envios e recepções de racionales decidendi entre as diversas correntes em vários países do mundo 5 .

A importância dos fatores extrainstitucionais não está no fato de vigorarem de fato determinado sistema, seja jurídico ou social, mas na virtualidade crítica que eles apresentam, ou seja, na capacidade intrínseca que eles detêm para justificar, do ponto de vista argumentativo, além de motivar do ponto de vista fático a ação dos aplicadores do direito, estimulando esse diálogo constitucional entre as cortes.

O diálogo internacional entre juízes está relacionado ao fenômeno da globalização ${ }^{6}$ que tende a planificar as relações humanas, fomentadas pela evolução dos meios de comunicação nas últimas décadas, o que facilitou sobremaneira o intercâmbio de dados e de experiências em todas as áreas. Especialmente, os órgãos judiciais como os tribunais constitucionais, cortes supremas e tribunais internacionais dispõem, hoje, de páginas oficiais na internet

5 RAMIRES, Maurício. Diálogo judicial internacional: o uso da jurisprudência estrangeira pela justiça constitucional. Rio de Janeiro: Lumen Juris, 2016, p. 7-8.

6 Conforme destaca TUSHNET, Mark. The Inevitable Globalisation of Constitucional Law. In: MULLER, Sam \& RICHARDS, Sidney (ed.). Highest Courts and Globalisation. The Hague: Hague Academic Press, 2010, p. 36. "A "conversação" internacional entre juízes é evidentemente relacionada com o fenômeno da globalização. A evolução dos meios de comunicação verificada nas últimas décadas facilitou sobremaneira o intercâmbio de dados e experiências em todas as áreas da atividade humana, e o direito constitucional não se manteve alheio a seu impacto. De certa forma, pode-se dizer que, dado o mundo "plano" em que se vive, a globalização do direito constitucional seria algo "inevitável"”. 
pelas quais divulgam sua jurisprudência para fácil acesso, gratuito e instantâneo.

Os participantes do discurso jurídico devem atentar para os fatores extrainstitucionais que podem corroborar para fundamentar a adesão a um diálogo internacional, como assevera Bustamante ${ }^{7}$ :

O só fato de esses fatores serem capazes de contribuir para a racionalização do Direito é uma razão para considera-los relevantes para a teoria normativa dos precedentes judiciais que busco construir. Como venho insistindo, a decisão jurídica é condicionada tanto por elementos ou razões de autoridade quanto por motivos puramente racionais (não institucionalizados).

Entretanto, para falar em diálogo, é necessário estabelecer uma linguagem que o instrumentalize, pela qual juízes e tribunais de diversas nações, com idiomas e culturas diversificadas, citem-se uns aos outros como autoridades argumentativas em assuntos constitucionais, produzindo uma espécie de conversação multilateral. É preciso que se estabeleça uma linguagem comum.

Em outras palavras, o entendimento e a compreensão entre os juízes e os tribunais do mundo pressupõem a existência de uma gramática compartilhada entre as ordens jurídico-constitucionais dos diversos países, que pode ser identificada como o Estado Democrático de Direito, fundamentados em sistemas principiológicos de tomada de decisão em direitos e garantias fundamentais.

A partir da ascendência do papel das Constituições, especialmente na segunda metade do século $\mathrm{XX}$, os vários sistemas jurídico-políticos de muitos países ganharam ou recuperaram um fundamento comum, qual seja, o movimento constitucionalista, e com ele um modo dialogal para solução de problemas constitucionais simultâneos.

No tocante à concepção do direito marcado por princípios que estimulam o diálogo, como leciona Ramires ${ }^{8}$ :

Permeabilizou as fronteiras das ordens jurídicas, considerando que as aplicações principiológicas têm uma dimensão mais cosmopolita do que as das provincianas regras jurídicas. Em suma, a tese, neste particular, é a de que o diálogo atualmente travado entre os juízes constitucionais é menos um produto das facilidades da era da informática do que do revigoramento do constitucionalismo a partir do segundo pós-guerra.

7 BUSTAMANTE, Thomas da Rosa de. Teoria do precedente judicial: a justificação e a aplicação de regras jurisprudenciais. São Paulo: Noses, 2012, p. 330-331.

8 RAMIRES, Maurício. Diálogo judicial internacional: o uso da jurisprudência estrangeira pela justiça constitucional, p.11. 
Desta forma, o constitucionalismo figura como uma ideologia de origem europeia, comum à configuração política ocidental, podendo ser resumida em dois pilares básicos: as noções de limitação do poder e de respeito a um núcleo fundamental de direitos. Essa ideologia conforma uma semântica também comum, que permite e mesmo estimula a comunicação entre os nacionais de diversos países no que se refere aos modos como deve ser entendido o Estado constitucional.

Trata-se, pois, da construção e do reconhecimento de uma tradição compartilhada. Afinal, nas palavras de Kaufmann", "a tradição é o terreno comum em que vivemos ${ }^{10 "}$ cujos Estados constitucionais que se pretendem democráticos e de direito partem das mesmas concepções de constitucionalismo.

Conforme destacado, o objetivo geral desta pesquisa é demonstrar a necessidade de se estabelecer um diálogo verdadeiro entre os tribunais, a fim de que os precedentes possam ser utilizados, como forma de efetivação dos direitos fundamentais.

Entretanto, o desafio está em estabelecer esse núcleo duro, respeitando as diferenças sociais, culturais, econômicas decorrentes de cada região, respeitando as diferenças para que se possa consagrar um direito comum, seja ele de origem Ocidental ou Oriental.

Como explica a ex-juíza da Suprema Corte canadense Claire L'heurex-Dubé ${ }^{11}$, o pioneirismo do Bill of Rights dos Estados Unidos, como o primeiro documento de sua natureza a ser interpretado e ganhar sentido por meio das decisões dos tribunais, "Tornou-se 'natural' que outros países olhassem para o seu texto e a interpretação que venceu nos tribunais dos EUA para elaborar seus próprios modelos de proteção e garantir direitos ${ }^{12 "}$.

De fato, o constitucionalismo norte-americano exerceu influência, incluindo o seu repertório de jurisprudência, desde muito tempo sobre o direito e a política da América Latina (por exemplo, no Brasil). O ato normativo que organizou a Justiça Federal e instalou o Supremo Tribunal Federal (Decreto n848, de 11 de outubro de 1890) já previa que a jurisprudência estrangeira, especialmente a

9 KAUFMANN, Arthur. Hermenéutica y derecho. Tradução de Luis Villar Borda e Ana Maria Montoya. Granada: Comares, 2007, p. 94 e 106.

10 "La tradición es el terreno común em el que vivimos".

11 L'HEUREUX-DUBÉ, Claire. The Importance of dialogue: globalization, the rehnquist court and Human Rights. In: (Org.) BELSKY, Martin H. The rehnquist court: a retrospective. New York: Oxford University Press, 2002, p. 234-235.

12 'It became 'natural' that other countries would look at your text and the interpretation that won in US courts to draft their own protection models and guarantee rights". 
norte-americana, deveria servir de fonte jurídica subsidiária nos provimentos judiciais federais ${ }^{13}$.

Os efeitos práticos dessa influência nas discussões constitucionais brasileiras do final do século XIX são bastante visíveis. Em 1893, naquela que é vista como a primeira vez em que foi arguido no foro brasileiro o direito dos tribunais de examinar a constitucionalidade dos atos legislativos ou administrativos e negarIhes execução ou manter contra eles o direito dos indivíduos, o advogado Rui Barbosa sustentava que "nossa lâmpada de segurança" deveria ser "o direito americano, suas antecedências, suas decisões, seus mestres"14. A tese foi tacitamente acolhida pelo Supremo Tribunal Federal ${ }^{15}$, em um curto acórdão considerado um dos marcos iniciais do controle judicial de constitucionalidade no Brasil.

Com isto, inaugurou-se uma projeção unilateral da jurisprudência norteamericana. Contudo, nos anos recentes, o incremento dos laços e das influências internacionais no direito tem afetado as decisões judiciais, especialmente no âmbito das cortes mais altas.

Nesse sentido, uma das novidades introduzidas pelo modelo do diálogo entre as cortes constitucionais, foi a chamada

[...] polinização cruzada, onde osjuízes não mais recebem, simplesmente, os casos de outras jurisdições, particularmente dos Estados Unidos, e, então, aplicam-nos ou modificam-nos para sua própria jurisdição. Ao contrário a polinização cruzada e o diálogo entre jurisdições estão ocorrendo crescentemente ${ }^{16}$.

Com efeito, dois fenômenos simultâneos têm se verificado nas últimas

13 Eis o texto do artigo 386, $2^{a}$ parte, daquele diploma legal: "Os estatutos dos povos cultos e especialmente os que regem as relações jurídicas na República dos Estados Unidos da América do Norte, os casos de common law e equity, serão também subsidiários da jurisprudência e processo federal".

14 Razões finais apresentadas perante a primeira instância em 1893 e publicadas sob o título Os actos inconstitucionaes do Congresso e do Executivo ante a Justiça Federal (Rio de Janeiro: Companhia Impressora, 1893; reproduzido em BARBOSA, Rui. Obras completas. v.XX, t.V, Rio de Janeiro: MEC, 1956). O pedido, fortemente embasado na doutrina inaugurada por John Marshall em Marbury v. Madison, consistia na declaração de nulidade do ato do Poder Executivo que reformou um Marechal das Forças Armadas contra sua vontade. Combatendo o alvitre contrário encampado pelo Procurador da República Rodrigo Octavio de Langgaard Menezes (que viria a ser nomeado Ministro do STF em 1929), Rui Barbosa alertava que os autores da Constituição brasileira eram discípulos de James Madison e Alexandre Hamilton, não de Jean-Jacques Rousseau e Gabriel Bonnot de Mably como o nobre procurador, que se aferrava à doutrina fatal da onipotência das assembleias, doutrina anacrônica e contrária ao nosso direito escrito.

15 AC n.112, j.19-09-1895. Jurisprudência, p. 189-191.

16 L'HEUREUX-DUBÉ, Claire. The Importance of dialogue: globalization, the rehnquist court and Human Rights, p. 234-235. 
décadas: o declínio da influência da jurisprudência da Suprema Corte dos Estados Unidos sobre suas congêneres de outras jurisdições, e o incremento das relações recíprocas dos outros tribunais do mundo.

Como exemplo, cita-se a decisão da Suprema Corte da Índia em Rajagopal v. State of Tamil Nadu (1995) ${ }^{17}$. Neste caso, os peticionários pretendiam uma ordem judicial para que os organismos estatais indianos abstivessem de tentar impedir a publicação da autobiografia de um criminoso condenado, na qual o autor declarava que autoridades públicas do país haviam cometido crimes em sua companhia. O Tribunal decidiu que os agentes públicos não podiam se insurgir contra a publicação de uma obra supostamente difamatória sobre sua atuação oficial, a não ser que conseguissem provar a falsidade da acusação e o fato de ter sido feita sem preocupação com a realidade.

De maneira similar, no caso Ferreira v. Levin $(1995)^{18}$, o Tribunal Constitucional da África do Sul lidava com questões de direito à liberdade e de proteção contra a autoincriminação. Em sua sentença invocou oito julgamentos da Suprema Corte dos Estados Unidos, entretanto, não considerou qualquer precedente da era mais recente de "Rehnquist".

A redução da influência da jurisprudência norte-americana pode ser relacionada tanto à mudança de paradigma na formação das Cartas Constitucionais, que passaram a adotar o modelo europeu; quanto à resistência da Suprema Corte americana em se engajar no diálogo judicial e admitir a recepção de influências externas.

Dessa maneira, Tribunais que se introduzem intensamente no diálogo internacional acabam ocupando novos espaços de influência, independentemente da posição de maior ou menor destaque político-econômico das nações na ordem mundial: é destacadamente o caso do Tribunal Constitucional da África do Sul e da Suprema Corte de Canadá ${ }^{19}$.

A existência de um denominador comum em questões de Direitos Humanos Fundamentais, além da "polinização cruzada" de Slaughter, fomenta a nova característica funcional que deve ser entendida como característica substancial:

17 [1995] 3 L.R.C. 566 apud RAMIRES, Maurício. Diálogo judicial internacional: o uso da jurisprudência estrangeira pela justiça constitucional, p. 107.

18 CCT 5/95, 1996 (1) AS 984 (CC) apud RAMIRES, Maurício. Diálogo judicial internacional: o uso da jurisprudência estrangeira pela justiça constitucional, p. 108.

19 Segundo Slaughter, (A new world order, 2004, p. 246), "Canada and South Africa - an old and a new democracy - with two new constitutional courts (the Canadian Supreme Court has existed since the mid-nineteenth century, but the new Constitution of Canada was enacted only in 1982, the Constitutional Court South African was created in 1994), each looking around the world and prospecting opinions from similar constitutional courts, and both disproportionately influential as a result". 
a repetição de problemas comuns em diversos países e a busca por soluções em uma tradição constitucionalista também compartilhada.

As trágicas consequências das experiências antidemocráticas do século $X X$ evidenciaram a muitas sociedades, nos diversos cantos do mundo, a necessidade de se criar um núcleo inderrogável de Direitos Humanos Fundamentais protegidos das disposições das maiorias, levando à recuperação de estruturas originais do constitucionalismo, readaptadas e desenvolvidas, em que as nações passam a (re)descobrir o que suas tradições jurídicas próprias tinham em comum.

Na formação desse diálogo, em especial na Europa, o caso da Alemanha merece especial destaque, por se tratar de outro país com arraigada tradição jurídica própria, que alcançou imensurável projeção internacional. O sistema jurídico comum da Europa continental e da América Latina é fundado no legado romano-germânico, em que,0 como ensina Miranda ${ }^{20}$ (2009, p. 178), "as decisões do Bundesverfassungsgericht, o Tribunal Constitucional Federal alemão, são hoje das mais citadas mundo afora, rivalizando em influência com as proferidas pela Suprema Corte dos Estados Unidos da América".

Ao contrário dos tribunais do Canadá e da África do Sul, ao fazer referência a precedentes estrangeiros, o Tribunal Constitucional germânico desenvolveu um estilo de fundamentação que cita basicamente apenas seus próprios precedentes. Contudo, para fundamentar suas decisões ${ }^{21}$, os juízes do tribunal utilizam consultas extensivas às fontes internacionais e estrangeiras.

Outra experiência interessante para demonstrar o crescente papel dos diálogos constitucionais pelo mundo é a francesa, que conta com um sistema de justiça constitucional original, exercido por um Conselho Constitucional, órgão político especialmente formado para o efeito da Constituição de 1958 e que, a partir de 1971, assumiu-se como órgão para-jurisdicional ou quase jurisdicional de fiscalização de constitucionalidade, embora apenas preventiva.

20 MIRANDA, Jorge. Manual de direito constitucional. t.I, preliminares; O Estado e os sistemas constitucionais. 8.ed. Coimbra: Coimbra, 2009, p. 178.

21 Por exemplo, em 2002 o BVerfG precisou decidir a respeito do caso de um açougueiro muçulmano turco que abatia animais à moda halal, para atender às convicções religiosas de sua clientela. Em virtude de que o ritual de abate alegadamente representava sofrimento adicional aos animais, e especialmente porque era dispensado pela própria autoridade religiosa islâmica no país, foi questionada a admissibilidade da conduta do açougueiro em relação à Lei de Proteção aos Animais. A decisão do Tribunal Constitucional, no sentido de que a prática estava protegida pelo direito de liberdade religiosa e não poderia ser proscrita pelo Estado, contrariou frontalmente expectativas de grupos sociais ruidosos, tanto de protetores dos animais quanto de setores xenófobos. Nesse contexto, os juízes alemães entenderam conveniente referir, em sua sentença, que o Tribunal Constitucional da Áustria também já decidira de forma semelhante. (RAMIRES, Maurício. Diálogo judicial internacional: o uso da jurisprudência estrangeira pela justiça constitucional, p. 134). 
A atuação do Conselho Constitucional, mesmo com todas as suas limitações, na avaliação de Favoreau"22, "consolidou no país o princípio da constitucionalidade, segundo a qual toda a autoridade (inclusive a do legislador) está sujeita à Constituição, com progressos espetaculares no campo da proteção das liberdades e direitos fundamentais".

No que se refere à recepção da experiência jurisdicional estrangeira, entretanto, o Conselho padece de pelo menos duas dificuldades estruturais não encontráveis nas demais cortes constitucionais do mundo: (a) a fiscalização de constitucionalidade francesa é um controle a priori que deve ser realizado em um prazo particularmente curto (de um mês em princípio, e de oito dias se o Governo declara urgência); (b) o órgão, provavelmente seguindo o exemplo do Conselho de Estado, normalmente tende a motivações muito concisas, que não são acompanhadas de eventuais votos divergentes ${ }^{23}$.

Assim, destaca-se que o Conselho Constitucional jamais citou explicitamente em suas sentenças algum precedente de outro tribunal nacional, mas, por outro lado, já encontrou espaço ao menos uma vez para uma referência expressa a uma decisão do Tribunal Europeu de Direitos Humanos ${ }^{24}$ e, em outra oportunidade, para um pronunciamento do chamado Tribunal de Justiça das Comunidades Europeias (atual Tribunal de Justiça da União Europeia) ${ }^{25}$.

Por contraste com seus colegas da Europa Central, os juízes constitucionais portugueses, em geral, não têm qualquer pudor ou reserva na invocação de julgados estrangeiros, colocando o Tribunal Constitucional de Portugal, sob este aspecto, na categoria a que pertencem o seu congênere sul-africano e a Corte Suprema canadense.

A realidade portuguesa é, de certa forma, como afirma Orrú26, "um dos pontos mais avançados do fenómeno da afirmação gradual de um círculo aberto (através das fronteiras nacionais) intérpretes da Constituição 27". Os motivos para

22 FAVOREAU, Louis. As cortes constitucionais. Tradução de Dunia Marinho Silva. São Paulo: Landy, 2004, p. 86.

23 CARPENTIER, Elice. La utilización de la jurisprudência constitucional extranjera por el consejo constitucional francés. Estudios Constitucionales, ano 7, n.2. Santiago do Chile, 2009, p. 132-133.

24 Decisão n 2004-505 DC de 19 de novembro de 2004 (Traité établissant une Constitution pour l'Europe), citando o caso do TEDH Leyla Sahin v. Turkey, App. n. 44774/98, sentença (4a Seção) de 29/06/2004.

25 Decisão $n^{\circ}$ 2005-531 DC de 29 de dezembro de 2005 (Loi de finances rectificative pour 2005), citando decisão do TJCE C-276/97, de 12 de setembro de 2000.

26 ORRÚ, Romano. La giustizia constituzionale in azione e il paradigma comparato: l'experienza portoghese. Revista da Faculdade de Direito da Universidade de Lisboa. Lisboa/Coimbra, v.42, n.1 e 2., 2006, p.303.

27 "Uno dei punti più avanzati del fenomeno della progressiva affermazione di un cerchio aperto (oltre i confini nazionali) interpreti della Costituzione". 
tal são de duas ordens: (a) atuam os elementos comuns a outros ordenamentos ocidentais em geral, especialmente a crescente integração internacional do direito público e a revolução tecnológica e de informação; (b) o fenômeno é favorecido por fatores particulares e específicos da realidade histórico-cultural portuguesa.

Como ilustração, há duas importantes decisões, espaçadas em quase sete anos entre si, concernentes à licitude de provas obtidas por interceptação de conversas telefônicas: o Acórdão no 407/97, que invoca os casos Olmstead v. United States (1928) e Katz v. United States (1967); e o Acórdão n¹98/04, que faz um apanhado da jurisprudência norte-americana sobre as teorias dos frutos da árvore envenenada e da regra de exclusão ${ }^{28}$.

Justamente nas questões sensíveis do ponto de vista sociopolítico é que o Tribunal Constitucional lusitano procura se valer de uma comparação com o estado da arte do tratamento do tema nos principais órgãos jurisdicionais dos países com grau equivalente de desenvolvimento jurídico-democrático.

Desta forma, ajurisprudência do Tribunal Constitucional português demonstra uma clara disposição do colegiado de envolver-se no diálogo constitucional travado nas principais democracias do mundo, em especial nos países centrais da Europa, e de contribuir para este debate.

O Supremo Tribunal Federal do Brasil assemelha-se ao Tribunal Constitucional de Portugal no que se refere às extensas invocações de julgados estrangeiros e às intensas influências que estes exercem sobre as decisões da Corte, manifestandose no Brasil a contingência da necessidade de lidar com uma Carta constitucional nova, pródiga na positivação dos direitos e garantias fundamentais, e com um passado autoritário que se manifestava nas práticas jurídicas vigentes há décadas.

A Carta da República de 1988 não alterou substancialmente o quadro institucional do Poder Judiciário doméstico, em especial, não criou um tribunal constitucional. O cume da hierarquia judiciária continuou pertencendo ao Supremo Tribunal Federal, que também manteve o poder, não exclusivo, mas último, de interpretação constitucional. Tampouco houve uma renovação imediata dos quadros do Supremo ou dos demais tribunais, de modo que os mesmos magistrados nomeados pelo regime militar permaneceram em seus postos, com a tarefa de interpretar o novo documento político.

Com o desenvolvimento da teoria constitucional brasileira e sua integração

28 RAMIRES, Maurício. Diálogo judicial internacional: o uso da jurisprudência estrangeira pela justiça constitucional, p. 146-147. 
no contexto mundial, além da renovação paulatina dos membros do Supremo Tribunal Federal, a jurisprudência da mais alta corte brasileira passou a alinhar-se com a preocupação de dar efetividade ao texto constitucional e aos direitos e garantias nela encerrados.

Nesse processo de autoafirmação da Corte e de definição de suas funções e técnicas de trabalho, o olhar voltado às práticas estrangeiras foi fundamental,

na Ação de Descumprimento de Preceito Fundamental (ADPF) n.130/ $\mathrm{DF}^{29}$, de grandes consequências para a matéria porque reconheceu a inconstitucionalidade superveniente da íntegra da Lei de Imprensa (Lei n. 5250, de 09 de fevereiro de 1967), o acórdão do Supremo Tribunal Federal faz menção a mais de uma dezena de precedentes norteamericanos, a uma mancheia de julgados do Tribunal Constitucional Alemão, além de sentenças da Câmara dos Lordes do Reino Unido, do Tribunal Constitucional da Espanha e do Tribunal Europeu de Direitos Humanos ${ }^{30}$.

Outro caso de grande repercussão foi o Habeas Corpus n 82.424 , no âmbito do qual se discutiu perante o Supremo ${ }^{31}$ se um sujeito que publicara livros com conteúdo discriminatório contra judeus praticara crime de racismo ou agira abrigado pela liberdade de manifestação de pensamento. $\mathrm{O}$ acórdão fez menção a 12 julgados estrangeiros, de diversos Tribunais.

De modo geral, as referências ao direito estrangeiro pelo Supremo Tribunal Federal,

Tornaram-se fartas, e não parecem obedecer a algum critério ou alguma ordem. Contudo na profusão de referências a materiais não-nacionais pelo colegiado, pode-se notar a relativamente pequena influência de algumas ordens jurídicas das quais era de se esperar uma presença mais marcante ${ }^{32}$.

29 ADPF n.130, Rel. Carlos Britto, Tribunal Pleno, julgado em 30/04/2009, DJe 06/11/2009.

30 RAMIRES, Maurício. Diálogo judicial internacional: o uso da jurisprudência estrangeira pela justiça constitucional, p. 152-153.

31 Mais importante, porém, foi a inserção do parágrafo seguinte na ementa da decisão: "A exemplo do Brasil as legislações de países organizados sob a égide do Estado Moderno de Direito Democrático igualmente adotam em seu ordenamento legal punições para delitos que estimulem e propaguem segregação racial. Manifestações da Suprema Corte Norte-Americana, da Câmara dos Lordes da Inglaterra e da Corte de Apelação da Califórnia nos Estados Unidos que consagraram entendimento que aplicam sanções àqueles que transgridem as regras de boa convivência social com grupos humanos que simbolizem a prática de racismo".

32 FIGUEIREDO, Marcelo. Notas a respeito da utilização de jurisprudência estrangeira pelo Supremo Tribunal Federal no Brasil. Revista Brasileira de Estudos Constitucionais, ano 3, n.12, Belo Horizonte, 2009, p. 57-69. 
Em relação aos demais tribunais na América do Sul, devido à proximidade geográfica, o que se esperava era um diálogo mais intenso e constante, também em razão da facilidade da linguagem, a formação histórica, as identidades jurídicas de tradição romano-germânica, as tentativas de integração políticojurídica, como o Mercosul e a inserção em uma mesma ordem supranacional de direitos humanos, com a vigência da Convenção Interamericana de Direitos Humanos e o reconhecimento da Corte Interamericana de Direitos Humanos.

Contudo, a perspectiva desse diálogo judicial foi uma frustração. No entendimento de Afonso da Silva ${ }^{33}$, "um claro déficit na integração jurídica na América do Sul é uma grande ausência de diálogo constitucional transnacional entre tribunais, o que resulta em uma quase total ausência de migração de ideias constitucionais na região".

Segundo o autor, pouco se sabe no Brasil sobre o que acontece nos países vizinhos e o que fazem os seus tribunais, embora com maior frequência se conheça o que escrevem os autores de países vizinhos, especialmente da Argentina. Apesar de manterem-se relativamente cientes da atividade do Tribunal Constitucional alemão ou da Suprema Corte dos Estados Unidos, os juristas brasileiros em geral não têm a menor ideia do que (e como) se decide na Corte Suprema de Justiça da Argentina, no Tribunal Constitucional do Chile ou na Corte Constitucional da Colômbia ${ }^{34}$.

Percebe-se uma abertura extremamente seletiva, e de certa forma, limitada, à influência estrangeira na jurisprudência nacional, pela qual o Supremo Tribunal Federal busca inspiração nos tribunais mais antigos, como o dos Estados Unidos, ou mais consagrados como o da Alemanha, mas descura de outras experiências mais próximas do ponto de vista geográfico, histórico ou cultural ${ }^{35}$.

Contudo, mesmo com toda a seletividade, isso não quer dizer que o Supremo Tribunal Federal não esteja incrementando suas relações recíprocas e engajandose crescentemente em diálogos umas com as outras, uma vez que as ausências

33 AFONSO DA SILVA, José. Curso de direito constitucional positivo. 39. ed. São Paulo: Malheiros, 2016, p. 522523.

34 O constitucionalista brasileiro ainda aponta: "nem mesmo por meio das decisões da Corte Interamericana as ideias migram de um país a outro, como costuma ocorrer na Europa por meio da jurisprudência do Tribunal Europeu de Direitos Humanos. No Brasil, a jurisprudência da Corte Interamericana de Direitos Humanos não tem ressonância nas decisões dos tribunais nacionais". (AFONSO DA SILVA, Curso de direito constitucional positivo. p. 523).

35 ANDRADE, Régis Willyan da Silva. A inderrogabilidade de direitos na ordem constitucional à luz do sistema jurídico multinível. Tese (doutorado em Direito Constitucional - Orientadora: Flávia Piovesan) - Pontifícia Universidade Católica de São Paulo. São Paulo, 2016, p. 297/299. 
apresentadas apenas demonstram que ainda há espaço para um aumento da integração e da troca de experiências, fomentando o diálogo e a criação de um núcleo inderrogável de Direitos Humanos Fundamentais na esfera internacional.

De certa forma, a falta de diálogo nas relações jurídicas entre os países vizinhos geograficamente ao Brasil se deve ao fato de que, nos últimos anos, diversos países da região têm sofrido revezes na governança democrática, com a ascensão de regimes políticos populistas e personalistas, como ocorre na Venezuela, Bolívia e Equador. Em menor grau este fenômeno também pode ser vislumbrado na Argentina.

Não é acidental que a doxa vigente nesses países seja infensa ao elemento estrangeiro, especialmente do oriundo das democracias desenvolvidas, conforme aponta Galeano ${ }^{36}$, "Isso ocorre porque as imagens que dá substância é um produto de uma arrogância revolucionária, que pretende romper com o passado de opressão e exploração por parte da Europa e dos Estados Unidos ${ }^{37 "}$.

Assim, os ideólogos dos novos regimes procuram exaltar os valores autóctones ou telúricos das culturas nacionais, por oposição aos importadores ou cultivadores de uma cultura estrangeira considerada por estes, decadente, e lutam contra a globalização, que, segundo eles, faz mais ricos os países ricos e mais pobres os países pobres.

Essa disseminação de uma cultura populista e personalista desenvolve um ideário de que a massa não consegue alcançar os bens pretendidos, porque os países desenvolvidos exploram os países em desenvolvimento, impedindo-os de conseguir prover todos os direitos e benesses de um regime democrático.

Na Venezuela, mudou-se a composição do Supremo Tribunal de Justiça como meio de assegurar a ascendência do governo sobre o colegiado, com a interferência direta do poder político sobre a magistratura, como a demissão e até mesmo a prisão de juízes por terem tomado decisões contrárias à vontade do então Presidente da República, casos que abalaram de forma considerável a percepção de independência do Poder Judiciário neste país.

36 GALEANO, Eduardo. Las venas abiertas de America Latina. Ciudad de México: Siglo XXI, 1971, p. 123.

37 "Esto se debe a que las imágenes que le da sustancia es um producto de una arrogancia revolucionaria, que desea romper con el supuesto pasado la opresión y la explotación impuesta por Europa y los Estados Unidos". 
Na Bolívia, por sua vez, as reformas implementadas a partir da nova Carta Constitucional, as quais incluíram o sufrágio popular para nomear juízes, têm gerado sérias dúvidas quanto à capacidade do Poder Judiciário de promover julgamentos isentos em casos politicamente carregados, havendo razões para antecipar que a estrutura judiciária possa se tornar um instrumento de vingança política, contra os adversários do regime.

Essas limitações impõem aos juízes das principais cortes dessas nações dificuldades no diálogo judicial, haja vista que, em razão da cooptação política ou coação, abstêm-se, em suas decisões de buscar uma integração na comunidade internacional, apenas referendando os anseios desses regimes populistas, como forma de legitimar o arbítrio do poder central ${ }^{38}$.

Há, contudo, exemplos positivos, com experiências virtuosas na América do Sul, como o Chile, que mesmo após um período de violação em massa aos Direitos Fundamentais, a partir do golpe de Estado que depôs o Presidente Salvador Allende, em 1973, instalou a ditadura do general Augusto Pinochet. O Chile encetou a abertura política em 1987, e a transição para a democracia ganhou corpo a partir do fim do governo do general, em $1990^{39}$.

O Tribunal Constitucional Chileno foi constituído pela reforma constitucional de 1970, anterior, portanto, ao regime militar, que suspendeu as garantias da Constituição de 1925 e dissolveu a Corte. Conforme descreve,

O funcionamento do Tribunal Constitucional do Chile passou por três fases: (a) a primeira (1970-1973) é o Tribunal de apenas cinco membros, a reforma constitucional de 1970 foi criada e conseguiu emitir apenas 17 pronunciamentos antes de ser dissolvido em novembro 1973; (B) a segunda fase (1981-2005) começa em 1981 com a instalação de sete Membros Tribunal ao abrigo do Capítulo VII da Constituição 1980, que trabalhou continuamente desde então, mas com alterações significativas em sua composição e as tarefas desde a reforma constitucional de 2005; (C) em 26 de fevereiro de 2006 começa o termo desta reforma e, com ele, a terceira etapa do Tribunal Constitucional, que deve funcionar é composto por dez membros, e um significativo aumento em suas habilidades ${ }^{40}$.

38 ANDRADE, Régis Willyan da Silva. A inderrogabilidade de direitos na ordem constitucional à luz do sistema jurídico multinível. p. 302/304.

39 ANDRADE, Régis Willyan da Silva. A inderrogabilidade de direitos na ordem constitucional à luz do sistema jurídico multinível. p. 315/316.

40 "El funcionamiento del Tribunal Constitucional de Chile ha pasado por três etapas: (a) la primera (1970-1973) es el Tribunal de sólo cinco miembros, se creó la reforma constitucional de 1970 y logrado emitir sólo 17 
No início da nova fase de atuação do Tribunal Constitucional Chileno, as citações de elementos estrangeiros ainda eram raras e, quando existentes, limitavam-se a reforçar a argumentação desenvolvida. Liliana Galdámez Zelada ${ }^{41}$, porém, observa que os anos de 2008 a 2010 registraram o "uso crescente", em quantidade e influência, desses elementos. A jurista chilena fez um levantamento quantitativo de referências encontráveis nesse período, que indica que a jurisprudência estrangeira mais citada nas sentenças é a espanhola, seguido da alemã e, depois, em grau equivalente, as de França e Itália.

O segundo exemplo sul-americano de integração no constitucionalismo contemporâneo, e na formação de um diálogo internacional, é a Colômbia, que tem um regime democrático antigo, mas suas instituições públicas apresentam um funcionamento precário.

A Corte Constitucional colombiana foi criada pela Constituição de 1991, vislumbrando tornar-se um dos tribunais mais ativistas do mundo. Sob essa ótica, constata-se que a referida Corte

\begin{abstract}
Atuou como substituto da legislação sobre diversas questões e diversas oportunidades por meio de injeção de políticas ao sistema, a gestão de questões políticas altamente complexas e policêntricas e o desenvolvimento de uma densa construção de direitos constitucionais, a Corte utiliza para controlar o Poder Executivo ${ }^{42}$.
\end{abstract}

Não há dúvida de que o recurso ao diálogo internacional é parte importante nesse processo de autoafirmação da Corte, haja vista que se inspirou na tradição do common law, por exemplo, para estabelecer efeitos vinculantes de seus próprios precedentes, além de que, assim como no Brasil, o controle de constitucionalidade colombiano é misto, com o controle abstrato e o concentrado convivendo entre si.

pronunciamientos antes de ser disuelto en noviembre 1973; (B) la segunda fase (1981-2005) se inicia con la instalación en 1981 de la Corte de siete membros establecidos en el Capítulo VII de la Constitución de 1980, que trabajó ininterrumpidamente desde entonces, pero con cambios sustanciales en su composición y tareas desde la reforma constitucional de 2005; (C) el 26 de febrero de 2006 comienza el mandato de esta reforma y, con ella, la tercera etapa de la Corte Constitucional, el cual deberá trabajar consta de diez miembros y um aumento significativo en sus habilidades" (TORRES PEREZ, A. Conflicts of rights in the European Union: a theory of supranational adjudication. Oxford: Oxford University Press, 2009, p. 209-210).

41 ZELADA, Liliana Galdámez. El uso del derecho y jurisprudencia estranjera en los falos del tribunal constitucional de Chile: 2006-2010. Revista Chilena de Derecho. Santiago de Chile, v.39, n.1., 2012, p. 193-192.

42 "It has acted as a substitute for legislation on various issues and various opportunities through policy injection to the system, the management of highly complex and polycentric political issues and the development of a dense construction of constitutional rights, the Court uses to control the Executive Branch". (LANDAU, David; LÓPESMURCIA, Julián Daniel. Political institutions and judicial role: an approach in context, the case of the Colombian Constitutional Court. Vnversitas. n.119. Bogotá, 2009, p. 57). 
Com vistas nessa ascendência do papel do juiz constitucional, o jurista colombiano Andrés Fajardo-Arturo considera que seu país tem experimentado uma "mudança de cultura jurídica", acompanhando a evolução do direito constitucional em âmbito mundial.

Para a consecução desse objetivo, a integração da aplicação do direito interno ao sistema interamericano de direitos humanos, em especial, e aquilo que o autor chama de "homogeneização" do direito constitucional, em geral, desempenham um papel fundamental ${ }^{43}$.

Desta forma, em maior ou menor grau, as Cortes Constitucionais têm buscado dialogar de forma a cruzar não apenas pensamentos, mas fundamentações para casos complexos envolvendo a proteção de Direitos Humanos Fundamentais, tanto num sistema mais antigo como o Europeu e o norte-americano, quanto nos sistemas embrionários latino-americanos.

Esse diálogo servirá de elo entre a criação de um núcleo inderrogável de direitos, por meio de uma Constituição Internacional, com um Tribunal Constitucional Internacional, que tenha mecanismos capazes de investigar, julgar e posteriormente aplicar sanções tanto aos indivíduos quanto aos Estados que violem esses direitos comuns, não ficando o Tribunal adstrito a questões a serem relativizadas, como a soberania, em favor de um bem maior, a proteção da humanidade.

Ao estabelecer esses parâmetros na efetivação dos Direitos Humanos Fundamentais, busca-se, dentre outros aspectos, a prevalência da autoridade do argumento e não do argumento da autoridade. Assim, países que não acompanharem as evoluções decorrentes de um constitucionalismo dinâmico, pautado no diálogo internacional, estão fadados à falência institucional e, consequentemente, à quebra da ordem democrática.

Ademais, para ampliar o controle de constitucionalidade a um sistema multinível, com aplicações domésticas e supranacionais, mais do que a criação de um núcleo inderrogável de direitos, é importante, por meio de uma Carta Constitucional Internacional, a criação de um Tribunal Constitucional Internacional como aplicador de um sistema jurídico multinível.

43 FARJARO-ARTURO, Luis Andrés. La influencia del Sistema Interamericano de los Derechos Humanos em el derecho constitucional colombiano: marco teórico. Revista colombiana de Derecho Internacional, n.12, Bogotá, 2008, p. 313-314. 


\section{O TRIBUNAL CONSTITUCIONAL INTERNACIONAL COMO APLICADOR DO SISTEMA JURÍDICO MULTINÍVEL}

Ao longo dessa sucinta pesquisa, constata-se que as Cortes Constitucionais no que tange à evolução do sistema de proteção dos Direitos Humanos Fundamentais foram acompanhadas pela criação de mecanismos visando à efetividade desses direitos nas hipóteses de violação tanto por parte dos Estados quanto por parte dos indivíduos.

A primeira jurisdição verdadeiramente internacional foi instituída em 1945 pelos aliados, mais precisamente pelos americanos, que criaram o primeiro tribunal internacional, e ocorreu em função da ideia de se punir os nazistas, manifestado por meio da Declaração de Moscou de 1943, sendo o Tribunal Militar Internacional instituído pelo Acordo de Londres de 1945.

Após a criação desse tribunal de exceção, as Nações Unidas concentraram seus esforços para estabelecer um tribunal penal internacional, que se manifestava basicamente em dois aspectos: codificar crimes internacionais e elaborar um projeto de estatuto para estabelecer um tribunal internacional.

Nesse processo foram elaborados os princípios decorrentes do Tribunal de Nuremberg, visando proteger crimes contra a paz e a segurança da humanidade, contudo encontrando fortes resistências devido à polarização ocorrida após o final da Segunda Guerra até a hecatombe da queda do muro de Berlim.

Enquanto o projeto de um Tribunal Internacional Penal se desenvolvia, foi criada uma corte com base ad hoc visando punir as atrocidades cometidas na antiga Iugoslávia, onde seriam processados quatro tipos de crimes: graves violações às Convenções de Genebra de 1949; violações às leis e aos costumes da guerra; crimes contra a humanidade e genocídio, com jurisdição limitada às violações ocorridas no território da antiga Iugoslávia a partir de 1991.

Baseado nesse tribunal de exceção, foi criado o segundo tribunal ad hoc, encarregado de processar e julgar as graves violações de direito humanitário cometidas em Ruanda e nos países vizinhos em 1994, em que, segundo Jankov44, "seu Estatuto assemelha-se ao do TPI, entretanto, os dispositivos relativos aos

44 JANKOV, Fernanda F.F. Direito internacional penal - mecanismos de implementação do Tribunal Penal Internacional. São Paulo: Saraiva, 2009, p. 26. 
crimes de guerra por refletirem o contexto de um conflito armado eminentemente interno, afastam as graves violações das Convenções de Genebra".

Nesse sentido, destaca-se a criação do Tribunal Penal Internacional por meio da Conferência de Roma, que em julho de 1998 aprovou o Estatuto do Tribunal, por 120 votos favoráveis e 7 contrários, a se destacar China, Estados Unidos, Filipinas, Índia, Israel, Siri Lanka e Turquia, além de 21 abstenções. Este foi considerado o ápice do desenvolvimento de uma instância superior de caráter internacional.

Desde 1948, com a adoção da Convenção para a Prevenção e a Repressão do Crime de Genocídio, era prevista a criação de uma Corte Penal Internacional ${ }^{45}$. Após 50 anos, em 1998, com a aprovação do Estatuto, criou-se, ineditamente, uma Corte de caráter permanente, independente e com jurisdição complementar às Cortes nacionais ${ }^{46}$.

Diferentemente dos Tribunais ad hoc criados na década de 1990 para julgar os crimes cometidos na ex-Iugoslávia e em Ruanda - cuja criação foi baseada em resoluções do Conselho de Segurança da ONU, para as quais é requerido o consenso de 5 membros permanentes, com poder de veto, nos termos do art. 27, $\S 3^{\circ}$, da Carta da ONU -, o Tribunal Penal Internacional,

45 A Convenção para a Prevenção e Repressão ao Crime de Genocídio foi adotada em 9 de dezembro de 1948. Prescreve ser o genocídio um crime que viola o Direito Internacional, o qual os Estados se comprometem a prevenir e punir. $\mathrm{O}$ artigo $2^{\circ}$ da Convenção entende por genocídio "qualquer dos seguintes atos, cometidos com a intenção de destruir, no todo ou em parte, um grupo nacional, étnico, racial ou religioso, tal como: a) assassinato de membros do grupo; b) dano grave à integridade física ou mental de membros do grupo; c) submissão intencional do grupo a condições de existência que lhe ocasionem a destruição física total ou parcial; d) medidas destinadas a impedir os nascimentos no seio do grupo; e e) transferência forçada de crianças de um grupo para outro grupo". Quanto ao julgamento do crime de genocídio, o artigo $6^{\circ}$ da Convenção estabelece: "as pessoas acusadas de genocídio serão julgadas pelos tribunais competentes do Estado em cujo território foi o ato cometido ou pela corte penal internacional competente com relação às Partes Contratantes que Ihe tiverem reconhecido a jurisdição". Constata-se, assim, que desde 1948 era prevista a criação de uma Corte Penal Internacional para o julgamento do crime de genocídio. O raciocínio era simples: considerando que o genocídio era um crime que, por sua gravidade, afrontava a ordem internacional e considerando ainda que, em face de seu alcance, as instâncias nacionais poderiam não ser capazes de processar e julgar seus perpetradores, seria razoável atribuir a uma Corte Internacional competência para fazê-lo. (PIOVESAN, Flávia. Direitos humanos e o direito constitucional internacional. 13. ed. São Paulo: Saraiva, 2012, p. 82-83).

46 O Tribunal Penal Internacional é integrado por 18 juízes com mandato de 9 anos. É composto pelos seguintes órgãos, nos termos do artigo 34 do Estatuto: a) Presidência (responsável pela administração do Tribunal); b) Câmaras (divididas em Câmara de Questões Preliminares, Câmara de Primeira Instância e Câmara de Apelações); c) Promotoria (órgão autônomo do Tribunal, competente para receber as denúncias sobre crimes, examiná-las, investigá-las e propor ação penal junto ao Tribunal); e d) Secretaria (encarregada de aspectos não judiciais da administração do Tribunal). 
Assenta-se no primado da legalidade, mediante uma justiça preestabelecida, permanente e independente, aplicável igualmente a todos os Estados que a reconhecem, capaz de assegurar direitos e combater a impunidade, especialmente a dos mais graves crimes internacionais. Consagra-se o princípio da universalidade, na medida em que o Estatuto de Roma se aplica universalmente a todos os Estados-partes, que são iguais perante o Tribunal Penal, afastando a relação entre "vencedores" e "vencidos"47.

Com isso se constata a complementariedade do Tribunal Penal Internacional, com o objetivo de efetivar os direitos consagrados nas Cartas Constitucionais, evitando-se assim a impunidade para os mais graves crimes internacionais, considerando que, por vezes, na ocorrência destes crimes, as instituições nacionais se revelam falhas ou omissas na solução das lides.

Desta feita, o Estado continua com a responsabilidade primária, o dever de exercer sua jurisdição penal contra os responsáveis por crimes internacionais, atribuindo-se à comunidade internacional a responsabilidade subsidiária, buscando assim equacionar o direito à justiça, o fim da impunidade e a soberania do Estado, à luz dos princípios da complementariedade e da cooperação.

De acordo com o artigo $5^{\circ}$ do Estatuto de Roma, compete ao Tribunal o julgamento dos seguintes crimes: a) crime de genocídio (tal como definido no artigo $2^{\circ}$ da Convenção para a Prevenção e Repressão do Crime de Genocídio de 1948); b) crimes contra a humanidade (incluindo ataques generalizados e sistemáticos contra a população civil, sob a forma de assassinato, extermínio, escravidão, deportação, encarceramento, tortura, violência sexual, estupro, prostituição, gravidez e esterilização forçadas, desaparecimento forçado, apartheid, entre outros crimes que atentem gravemente contra a integridade física ou mental); c) crimes de guerra (violações ao Direito Internacional Humanitário, especialmente às Convenções de Genebra de 1949); e d) crimes de agressão (ainda pendentes de definição nos termos do artigo $5^{\circ}$, 2, do Estatuto).

Por se tratar de jurisdição complementar, estabelece o artigo 17 do Estatuto que, dentre os requisitos de admissibilidade, deve haver a indisposição do Estado-parte, que pode ocorrer em razão de demora injustificada ou por falta de imparcialidade no julgamento; ou sua incapacidade em proceder à investigação 47 PIOVESAN, Flávia. Direitos humanos e o direito constitucional internacional, p. 83. 
e ao julgamento do crime, que ocorre quando há o colapso total ou substancial do sistema nacional de justiça.

Outro aspecto relevante do Tribunal Penal Internacional refere-se às penas. O Estatuto estabelece como regra a pena privativa de liberdade até 30 anos, admitindo excepcionalmente a prisão perpétua, quando justificada pela extremidade do crime e pelas circunstâncias pessoais do condenado (artigo 77), podendo ainda, além das sanções penais aplicáveis, impor sanções de natureza civil, determinando a reparação às vítimas e aos seus familiares (artigo 75), conjugando desta forma a justiça retributiva com a reparatória.

Desde a sua criação, mais de 1.700 denúncias de indivíduos e organizações não governamentais de Direitos Humanos, provenientes de mais de 100 países, haviam sido recebidas pela Promotoria do Tribunal Penal Internacional, que após análise meticulosa, concluiu que mais de $80 \%$ destas não eram de competência do Tribunal. Destacaram-se, apenas, os casos envolvendo a República Democrática do Congo, em 2004; República de Uganda, em 2004; e República Centro Africana, em 2005. Ademais, a Promotoria ainda instaurou uma investigação para analisar supostos crimes internacionais ocorridos no Quênia entre 2007-2008; em 2011 na Líbia e na Costa do Marfim.

Desta forma, existem no plano internacional, ferramentas e mecanismos para analisar crimes cometidos contra a humanidade, contudo, conforme disposição do próprio Estatuto, limitado a um determinado rol de crimes, entendidos como graves crimes internacionais.

Só então é possível chegar a uma das propostas desta pesquisa: a criação de um Tribunal Constitucional Internacional, pautado num núcleo inderrogável de direitos, cuja jurisdição seja universal, que possa atuar no sistema multinível, de maneira infra e supranacional, observando-se a soberania estatal, mas ampliando a possibilidade de proteção de Direitos Humanos Fundamentais consagrados numa Carta Constitucional Internacional.

O Estado constitucional, a partir dessa premissa, é necessariamente um que ao mesmo tempo recepciona e nutre características construídas em uma tradição que ultrapassa características temporais e fronteiriças, ou seja: limitação de poder, democracia, direitos e garantias fundamentais: 
A ideia da lei como expressão da soberania popular viu-se ultrapassada pela integração do direito numa comunidade política supranacional. 0 direito já não se encontra à disposição da vontade popular. A soberania dos representantes do povo encontra-se limitada por princípios que constam desses diversos textos (Constituições e declarações internacionais de direitos) cujo enunciado possui uma forte densidade moral. Os princípios comuns são a base de um novo pacto entre as nações, de modo que os textos constitucionais tornam-se a fonte em que os juízes procuram inspiração para os seus juízos, para além do Estado que os criou ${ }^{48}$.

A criação desse núcleo inderrogável de direitos em âmbito internacional deverá considerar as diferenças culturais, sociais, étnicas e econômicas, a fim de estabelecer não apenas uma igualdade formal, mas também material, destacandose, dentre outros, o direito à vida, à saúde, à segurança, ao trabalho e à moradia, assim como as liberdades de expressão, pensamento, reunião, entre outros.

Com isso, busca-se não um rol taxativo de direitos pautados apenas nas regras, mas em princípios, como enunciados normativos, capazes de orientar a uma interpretação extensiva, pautados na dignidade da pessoa humana, valorizando o homem em detrimento de pseudointeresses coletivos que trazem prejuízos à humanidade.

Com a instauração das Constituições modernas, o fenômeno jurídico inserese em dimensões bem mais vastas que aquelas, rigidamente nacionais, do legalismo positivista. Assim, na "relatividade" dos princípios constitucionais,

Está também o seu destino de natural disposição para a universalidade ou, pelo menos, internacionalidade ou supranacionalidade. Se há um campo em que a sensibilidade, a cultura e a realidade mesma dos homens foram e vão rapidamente se internacionalizando, este é, certamente, o campo das normas e dos institutos, dos valores e dos princípios de caráter constitucional ${ }^{49}$.

A importância da criação de um Tribunal Constitucional Internacional está em reconhecer que a evolução do constitucionalismo levou a uma mutação que busca não apenas positivar os direitos, mas efetivá-los. Entretanto, o Tribunal Penal Internacional, conforme previsto no Estatuto de Roma, não tem o arcabouço

48 ANTOINE GARAPON. O guardador de promessas: justiça e democracia. Tradução de Francisco Aragão. Lisboa: Instituto Piaget, 1998, p. 36-40.

49 CAPPELLETTI, Mauro. O controle judicial de constitucionalidade das leis no direito comparado. Tradução de Aroldo Plínio Gonçalves. 2.ed. Porto Alegre: Sérgio Antonio Fabris, 1999, p. 13. 
de solucionar todas as questões, mas somente aqueles mais relevantes no plano internacional, relacionados a crimes cometidos contra a humanidade.

A aplicação do direito pelos juízes em decorrência da evolução do constitucionalismo tem se afastado das condicionantes estritamente locais e ganha um horizonte mais amplo. Nesse sentido, na visão de Ramires ${ }^{50}$, "a verificação de uma comunidade supranacional de princípios jurídicos comuns e superiores às regras paroquiais seja uma reminiscência do universalismo jusnaturalista, tanto medieval quanto moderno".

A relação do constitucionalismo com os ideais racionalistas que o inspiraram, especialmente a partir da criação da semântica comum, possibilita o diálogo judicial internacional. Destaca-se, todavia, que este interconstitucionalismo contemporâneo não se confunde com o direito natural.

A justiça constitucional é uma forma de superar o legalismo, além de superar a arcaica concepção jusnaturalista de um direito absoluto e eterno, sem imposições universais nem desprezo por particularidades. Ao contrário, é uma construção conjunta de interpretações das Constituições dos Estados, visando reforçar e justificar a sua aplicação.

Assim, com a criação de um Tribunal Constitucional Internacional, pautado num núcleo inderrogável de direitos e a partir da atuação de um sistema multinível de proteção, os Estados passarão a um novo estágio de evolução do constitucionalismo: o da relativização do conceito de soberania, para um sistema dinâmico que acompanha as necessidades da coletividade na efetivação desses direitos, assim como na proteção contra os crimes cometidos contra a humanidade.

CONSIDERAÇÕES FINAIS

A evolução dos Direitos Humanos em âmbito internacional trouxe à tona a discussão acerca de como os tratados e as convenções que versarem acerca desses direitos em âmbito internacional serão incluídos em âmbito doméstico, no qual cada Estado tem adotado medidas específicas no que tange à recepção desses instrumentos internacionais.

50 RAMIRES, Maurício. Diálogo judicial internacional: o uso da jurisprudência estrangeira pela justiça constitucional. p. 102-103. 
O Brasil, assim como outras nações, passou por um processo de amadurecimento das teorias de recepção dos tratados internacionais relacionados aos Direitos Humanos, com avanços e retrocessos, até a promulgação da Emenda Constitucional $n^{\circ} 45 / 2004$, que buscou trazer um fim a essa discussão, ao introduzir o $\$ 3^{\circ}$ no artigo $5^{\circ}$ da Constituição da República de 1988, atribuindo status de Emenda Constitucional aos tratados e às convenções internacionais que versem sobre esses direitos.

Essa abertura constitucional permitiu aumentar o leque de proteção dos Direitos Humanos Fundamentais, além da inserção de novas formas de proteção, como o sistema multinível, exercidos pelos tribunais comuns, pelos tribunais de justiça constitucionais e pelos tribunais internacionais. Estabeleceu-se assim uma dependência da positivação desses direitos em instrumentos internacionais e, posteriormente, a inclusão nas Cartas Constitucionais.

A Constituição da República de 1988 passou por profundas transformações que visavam, além de reestabelecer a democracia após um tenebroso período militar, criar um núcleo inderrogável de direitos, dispondo de dispositivos específicos, como o art. $5^{\circ}$, além do art. $60, \S 4^{\circ}$ que os torna inderrogáveis.

Além disso, o Poder Judiciário, na sua evolução histórica, desempenhou um papel diferenciado, tendencialmente ativo, a fim de concretizar e implementar os direitos e as garantias consagrados na Constituição, por meio de normas e princípios norteadores.

Para efetivar os direitos consagrados na Constituição da República de 1988, apesar de não haver sido criado um Tribunal Constitucional, o Supremo Tribunal Federal avocou para si a responsabilidade de não só receber os tratados quanto de decidir relativamente a efetivação dos Direitos Humanos Fundamentais. É relevante sua atuação, tanto pela garantia dos direitos individuais quanto da efetivação de políticas públicas, que permitam estabelecer uma ordem social, em que a igualdade seja efetivamente concretizada.

O processo de globalização e internacionalização da jurisprudência constitucional levou à extensão que ultrapassa os limites domésticos dos 
entendimentos em sentenças ou precedentes que versam sobre interpretação constitucional. Desta forma, as decisões proferidas em âmbito doméstico acerca de questões de aspecto constitucional têm influência em outras Cortes Constitucionais, em casos complexos de efetividade dos Direitos Humanos Fundamentais.

Entretanto, para haver essa internacionalização, é necessário um diálogo entre as Cortes constitucionais, fomentando a comunicação e o intercâmbio de dados e experiências em todas as áreas. Especialmente, os órgãos judiciais, os tribunais constitucionais, cortes supremas e tribunais internacionais buscam fundamentar suas decisões em consonância não apenas com o direito doméstico, mas de acordo com que as demais Cortes Constitucionais têm decido.

Assim, por meio da troca dessas experiências constitucionais e de suas jurisprudências, em maior ou menor grau de interlocução, fomentam um movimento constitucional dinâmico, capaz de atender às necessidades da coletividade, por meio da criação de uma Constituição Internacional e de seu respectivo Tribunal Constitucional, a fim de estabelecer um núcleo inderrogável de direitos e propiciar a aplicação de um sistema jurídico multinível.

\section{REFERÊNCIAS DAS FONTES CITADAS}

AFONSO DA SILVA, José. Curso de direito constitucional positivo. 39.ed. São Paulo: Malheiros, 2016. ANDRADE, Régis Willyan da Silva. A inderrogabilidade de direitos na ordem constitucional à luz do sistema jurídico multinível. Tese (doutorado em Direito Constitucional - Orientadora: Flávia Piovesan) - Pontifícia Universidade Católica de São Paulo. São Paulo. 2016.

ANTOINE GARAPON. O guardador de promessas: justiça e democracia. Tradução de Francisco Aragão. Lisboa: Instituto Piaget, 1998.

BARBOSA, Rui. Obras completas de Rui Barbosa. v.XX, t.V. Rio de Janeiro: MEC, 1956. Disponível em: <http://docvirt.com/docreader.net>. Acesso em: 27 set.2016.

BUSTAMANTE, Thomas da Rosa de. Teoria do precedente judicial: a justificação e a aplicação de regras jurisprudenciais. São Paulo: Noses, 2012.

CAPPELLETTI, Mauro. O controle judicial de constitucionalidade das leis no direito comparado. Tradução de Aroldo Plínio Gonçalves. 2.ed. Porto Alegre: Sérgio Antonio Fabris, 1999. 
CARPENTIER, Elice. La utilización de la jurisprudência constitucional extranjera por el consejo constitucional francés. Estudios Constitucionales, ano 7, n.2. Santiago do Chile, 2009.

FARJARO-ARTURO, Luis Andrés. La influencia del Sistema Interamericano de los Derechos Humanos em el derecho constitucional colombiano: marco teórico. Revista colombiana de Derecho Internacional, n.12, Bogotá, 2008.

FAVOREAU, Louis. As cortes constitucionais. Tradução de Dunia Marinho Silva. São Paulo: Landy, 2004.

FIGUEIREDO, Marcelo. Notas a respeito da utilização de jurisprudência estrangeira pelo Supremo Tribunal Federal no Brasil. Revista Brasileira de Estudos Constitucionais, ano 3, n.12, Belo Horizonte, 2009.

GALEANO, Eduardo. Las venas abiertas de America Latina. Ciudad de México: Siglo XXI, 1971. JANKOV, Fernanda F.F. Direito internacional penal - mecanismos de implementação do Tribunal Penal Internacional. São Paulo: Saraiva, 2009.

KAUFMANN, Arthur. Hermenéutica y derecho. Tradução de Luis Villar Borda e Ana Maria Montoya. Granada: Comares, 2007.

LANDAU, David; LÓPES-MURCIA, Julián Daniel. Political institutions and judicial role: an approach in context, the case of the Colombian Constitutional Court. Vnversitas. n.119. Bogotá, 2009.

L'HEUREUX-DUBÉ, Claire. The Importance of dialogue: globalization, the rehnquist court and Human Rights. In: (Org.) BELSKY, Martin H. The rehnquist court: a retrospective. New York: Oxford University Press, 2002.

MIRANDA, Jorge. Manual de direito constitucional. t.I, preliminares; O Estado e os sistemas constitucionais. 8.ed. Coimbra: Coimbra, 2009.

PIOVESAN, Flávia. Direitos humanos e o direito constitucional internacional. 13.ed. São Paulo: Saraiva, 2012.

RAMIRES, Maurício. Diálogo judicial internacional: o uso da jurisprudência estrangeira pela justiça constitucional. Rio de Janeiro: Lumen Juris, 2016.

SLAUGHTER, A.M. A typology of transjudicial communication. University of Richmond Law Review. v.29, n.99. Richmond, 1994.

; BURKE-WHITE, W.W. The future of international law is domestic (or, the european way of law). Harvard International Law Journal 47, n.2, 2006.

TORRES PEREZ, A. Conflicts of rights in the European Union: a theory of supranational adjudication. Oxford: Oxford University Press, 2009. 
TUSHNET, Mark. The Inevitable Globalisation of Constitucional Law. In: MULLER, Sam \& RICHARDS, Sidney (ed.). Highest Courts and Globalisation. The Hague: Hague Academic Press, 2010.

ORRÚ, Romano. La giustizia constituzionale in azione e il paradigma comparato: l'experienza portoghese. Revista da Faculdade de Direito da Universidade de Lisboa. Lisboa/Coimbra, v.42, n.1 e 2., 2006.

ZELADA, Liliana Galdámez. El uso del derecho y jurisprudencia estranjera en los falos del tribunal constitucional de Chile: 2006-2010. Revista Chilena de Derecho. Santiago de Chile, v.39, n.1., 2012.

Recebido em: novembro/2017

Aprovado em: abril/2018 